\title{
FÓRUM
}

Artigo convidado

Versão origginal | DOI: https://doi.org/10.12660/cgpc.v27n87.85351

\section{A PANDEMIA E O FUTURO DO FEDERALISMO BRASILEIRO}

Eduardo José Grin | eduardo.grin@fogv.br | ORCID: 0000-0002-0488-8487

Antônio Sérgio Araújo Fernandes² | antoniosaf@ufba.br | ORCID: 0000-0002-4171-7759

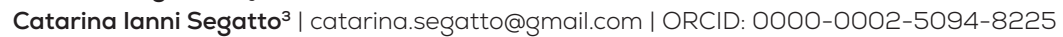

Marco Antônio Carvalho Teixeira ${ }^{1}$ | marco.teixeira@fgrv.br | ORCID: 0000-0003-3298-8183

Alex Bruno Ferreira Marques do Nascimento 4 | alex.bruno@professor.ufcg.edu.br| ORCID: 0000-0001-9860-7350

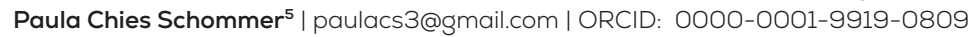

${ }^{1}$ Fundação Getulio Vargas, Escola de Administração de Empresas de São Paulo, SP, Brasil

¿Universidade Federal da Bahia, Escola de Administração, Salvador, BA, Brasil

${ }^{3}$ Universidade Federal do ABC, Programa de Pós-Graduação em Políticas Públicas, Santo André, SP, Brasil

${ }^{4}$ Universidade Federal de Campina Grande, Programa de Pós-Graduação em Administração, Campina Grande, PB, Brasil

EUniversidade do Estado de Santa Catarina, Centro de Ciências da Administração e Socioeconômicas, Florianópolis, SC, Brasil

\section{O QUE NORTEIA ESTA EDIÇÃO ESPECIAL}

A pesquisa acadêmica sobre federalismo no Brasil teve um significativo avanço desde a promulgação da Constituição Federal de 1988 (CF/88). Inicialmente, os estudos chamavam a atenção para as potencialidades da descentralização de políticas públicas como um mecanismo de democratização, participação social, accountability e atendimento às demandas locais. Uma série de estudos entre a década de 1990 e meados dos anos 2000, incluindo alguns resultantes do Ciclo de Premiações Gestão Pública e Cidadania (CEAPG, 2021), apontava para a atuação dos governos locais na inovação de políticas públicas.

Ainda que tenham havido avanços nas políticas locais nesse contexto, como formas de cooperação intermunicipal e de participação social, a literatura também apontou que a descentralização não necessariamente produziu democratização, que também dependia de outros fatores, especialmente de capacidades administrativas e fiscais municipais (Arretche, 1996). Além disso, a prevalência da competição entre as cidades, sem coordenação nacional, incentivou um municipalismo autárquico (Fernandes \& Wilson, 2013).

Na década de 1990, o debate concentrou-se na compreensão dos efeitos da descentralização nas políticas públicas e na democratização no nível subnacional de governo. A partir de 1995, com a mudança nos padrões de relacionamento intergovernamental e o aumento da coordenação nacional em áreas como saúde e educação (Abrucio, 2005), a literatura passou a incorporar, também, a compreensão dos efeitos dessa dinâmica federativa nas políticas públicas.

A centralidade que o governo federal passou a ocupar após 1995 não foi resultado de uma mudança significativa no desenho institucional do federalismo brasileiro, pois a CF/88 já definia competências compartilhadas, sobretudo nas políticas de bem-estar social. A principal alteração ocorreu com o desenvolvimento de mecanismos de coordenação intergovernamental que passaram a ser assumidos pelo governo federal. Contudo, algumas políticas caracterizadas por trajetórias centralizadas, em que o governo federal era o principal tomador de decisão, assim 
permaneceram, como é o caso da previdência social (tal como antes de 1988) e do Benefício de Prestação Continuada, BPC (implementado após 1988) (Arretche, 2012).

É importante apontar que, do final da década de 1990 até meados dos anos 2000, diversas mudanças reforçaram a centralidade dos municípios na provisão de políticas públicas que permanecem até hoje (por exemplo, a EC 29 na área da saúde). Associada à visão de que a municipalização reforçaria os efeitos positivos da descentralização, a estratégia encontrada para a universalização de políticas públicas foi sua a expansão para os municípios via indução e coordenação federal.

Os mecanismos de coordenação nacional adotados ao longo de mais duas décadas - de 1995 a 2016 - buscaram avançar nas determinações constitucionais de universalização dos direitos sociais. Em um primeiro momento, ainda na década de 1990, o fortalecimento da coordenação nacional, principalmente por meio de parâmetros nacionais de políticas públicas, redistribuição de recursos e combinação de transferências voluntárias a programas federais, foi central para expandir a cobertura na saúde e de matrículas, especialmente no ensino fundamental. Nos anos 2000, houve continuidade em relação ao fortalecimento da coordenação nacional, que buscou ampliar a expansão da cobertura das políticas. Por exemplo, a indução federal visando à ampliação de vagas na educação infantil e no ensino médio e a institucionalização da política de assistência social. Também foram adotadas medidas buscando melhorar a qualidade das políticas públicas para promover equidade e inclusão (Arretche, Marques, \& Faria, 2019).

Assim, a agenda de pesquisa esteve mais centrada na discussão dessas mudanças no nível nacional, incluindo análises sobre os processos decisórios que levaram à construção dos sistemas nacionais de políticas públicas, principalmente do Sistema Único de Saúde (SUS) (Viana et al., 2008), do Sistema Único de Assistência Social (SUAS) (Bichir, Simoni Júnior, \& Pereira, 2020) e da participação dos municípios como implementadores dessas políticas (Arretche, 2012). Alguns estudos avançaram na discussão sobre os efeitos desses processos, mostrando que o fortalecimento da coordenação nacional foi capaz de reduzir desigualdades regionais (Arretche, 2012) e contribuir para desenvolver capacidades estatais dos governos subnacionais (Grin \& Abrucio, 2018) nas políticas nacionalmente coordenadas.

A literatura também mostra que houve avanços na cooperação e coordenação no nível subnacional por meio de consórcios intermunicipais, associações de municípios, conselhos de secretários estaduais e municipais, conselhos de prefeitos, arranjos produtivos locais, comitês de bacia hidrográfica, coordenadorias ou agências metropolitanas, regiões integradas de desenvolvimento, fóruns federativos, entre outros tipos de arranjos. Alguns resultaram da indução federal e/ou de governos estaduais (Abrucio, Sano, \& Sydow., 2010; Grin, 202la; Julião \& Olivieri, 2020, Lui, Schabbach, \& Nora, 2020).

Quanto ao papel dos Estados nas políticas públicas, especialmente de sua atuação coordenadora com os municípios, há poucos estudos sobre o tema. Isso porque os Estados não estiveram no centro da formulação e implementação da maioria das políticas nas últimas décadas, ainda que tenham havido iniciativas, como o Pacto pela Saúde, em 2006, que buscaram reforçar esse papel. Contudo, a atuação estadual na oferta e coordenação de políticas públicas é bastante heterogênea (Licio, Palotti, Meneses, \& Pontes, 2021; Segatto, 2018; Segatto \& Abrucio, 2018; 
Silva, 2020). Em alguns casos, como no Ceará, a coordenação do governo estadual foi capaz de diminuir desigualdades intermunicipais na educação (Segatto, 2018; Segatto \& Abrucio, 2018).

Como resultado dessas quase três décadas de mudanças, construiu-se um modelo mais cooperativo de federalismo no Brasil, que combinou compartilhamento de competências, descentralização da implementação das políticas e coordenação nacional em que os mecanismos redistributivos e de indução foram centrais.

Contudo, as dinâmicas federativas vêm sendo alteradas desde 2016 e, especialmente, 2019. Desde 2016, após a aprovação da "Emenda do Teto dos Gastos", houve diminuição das transferências federais que induziam a implementação de políticas públicas, a exemplo da saúde, no nível subnacional. Já em 2019, com o início do governo Bolsonaro, ocorreu uma mudança radical no papel da coordenação federativa desempenhado pelo governo nacional. Adotou-se um modelo que centralizou decisões consideradas estratégicas pelo governo federal, o que enfraqueceu a coordenação nacional em áreas como saúde, educação e assistência social. Um dos efeitos da descoordenação federativa foi terem os governos subnacionais buscado ocupar vácuos de atuação da esfera central (Abrucio, Grin, Franzese, Segatto, \& Couto, 2020).

A pandemia da COVID-19 acabou por acelerar e ampliar a crise federativa desencadeada pelo governo federal desde 2019, que ficou evidenciada na falta de coordenação nacional, sobretudo na gestão da crise sanitária. Isso se mostrou nos entraves e nas dificuldades na execução de serviços compartilhados pelas três esferas - União, Estados e municípios. O governo Bolsonaro buscou romper com o modelo de articulação interfederativa existente no país, na contramão dos ganhos de federative policy learning construdos nas últimas décadas, especialmente pelos sistemas nacionais de políticas públicas. Estudos recentes mostram que a ausência de coordenação nacional produziu respostas fragmentadas, permeadas pela competição entre os níveis de governo, empurra-empurra, credit claiming e blaime avoidance (Abrucio et al., 2020; Abrucio, Grin, \& Segatto., 2021; Béland, Rocco, Segatto, \& Waddan, 2021).

Apesar desse cenário, observam-se experiências locais e cooperadas entre Estados e municípios, visando a desvencilhar-se da inação e negligência oriundas da descoordenação promovida pelo governo federal. Essas experiências, contudo, também evidenciam conflitos entre as esferas estaduais e municipais em ações destinadas a mitigar os efeitos da pandemia (Gil, 2021). Governos estaduais e municipais lidam com uma realidade muito complexa em que, mesmo agindo de forma responsável, encontram óbices de descoordenação e conflito interfederativo. Essa situação foi exacerbada no combate à pandemia.

Nessa linha, esta edição especial visa a analisar a crise federativa no Brasil que foi instalada no país durante o enfrentamento da pandemia da COVID-19. Buscou-se trazer estudos e reflexões focadas em explicar essa crise, bem como apontar saídas encontradas pelos entes federados diante dos problemas enfrentados, além de sugerir perspectivas para o estudo do federalismo.

A proposta desta edição pautou-se em temas centrais da discussão sobre o federalismo na pandemia: coordenação federativa e o papel do governo federal; conflitos jurisdicionais entre Estados e municípios; papel e atuação do SUS no enfrentamento à COVID-19; o papel dos Estados e as formas de cooperação e coordenação no nível subnacional para o enfrentamento da pandemia; políticas adotadas por Estados e municípios, visando ao bem-estar social e à mitigação 
de desigualdades socioeconômicas e inovação subnacional, instrumentos e mecanismos de coordenação desenvolvidos. Dos seis artigos aprovados, associados a esses temas e apresentados adiante, cinco deles abordam o federalismo brasileiro durante a pandemia de Covid-19 e um aborda a experiência mexicana na atual pandemia, comparando-a com a resposta anterior à Influenza A/H1Nl. Esta edição especial conta, ainda, com um artigo convidado, do Fórum das Federações, que apresenta um panorama do combate à pandemia de COVID-19 em 24 países federais ou com arranjos de organizações territorial do Estado similares.

Além desta introdução, este artigo está organizado em mais sete seções. A primeira discute a concepção do federalismo bolsonarista que vinha sendo gestada em 2019, mas que ganhou contornos mais nítidos com a pandemia, em função da descoordenação e do conflito intergovernamental implementado pela esfera central. Três artigos desta edição especial estão diretamente relacionados a esse tema.

A segunda trata dos conflitos jurisdicionais entre União, Estados e municípios durante a pandemia, incluindo a atuação do Supremo Tribunal Federal (STF) em litígios federativos, mas cujo comportamento histórico é marcado por decisões em favor da União. O destaque, durante a pandemia, foi a decisão de garantir a Estados e municípios autonomia para lidar com medidas restritivas, com base no artigo 23 da CF/88. Digna de nota pela sua característica em favor dos governos subnacionais, importa observar se ela foi tópica ou pode indicar uma inflexão da trajetória marcada por decisões pró-governo central. Um dos artigos desta edição especial analisa a atuação do STF, enquanto outro aborda o papel do Judiciário na solução de conflitos interfederativos na pandemia a partir de dados da Justiça estadual e da Justiça federal no Rio Grande do Norte.

A terceira seção aborda o papel do Sistema Único de Saúde (SUS) no enfrentamento à COVID-19, argumentando que a resiliência institucional do sistema, bem como de seus arranjos de cooperação federativa, têm sido peças-chave para mitigar o que poderia ser uma crise sanitária ainda maior.

A quarta enfatiza o papel dos Estados e as formas de cooperação e coordenação no nível subnacional para o enfrentamento da pandemia. No Brasil, esse foi um efeito não intencional que resultou da omissão e do conflito gerado pelo presidente Bolsonaro, pois incentivou o fortalecimento de arranjos consorciados, como ocorreu com os Estados do Nordeste. Em outros países, a cooperação e coordenação subnacional também foram demandadas na resposta a pandemias, como é analisado em artigo sobre o México.

A seguinte seção discute as políticas adotadas por governos subnacionais, visando ao bemestar social e à mitigação de desigualdades socioeconômicas durante a pandemia, que são responsabilidades desses níveis de governo, mas que, sem coordenação federal, produziram respostas fragmentadas e emergenciais.

Em seguida, aborda-se o tema da inovação subnacional, dos instrumentos e mecanismos de coordenação desenvolvidos na pandemia.

Na sétima seção, é apresentado o artigo convidado, que compõe esta edição especial, contendo um panorama do combate à pandemia de COVID-19 em 24 países e características de cada arranjo federal nesse processo. 


\section{AUSÊNCIA DE COORDENAÇÃO FEDERATIVA NA PANDEMIA: INNACTION POLICY, CONFLITO E NEGACIONISMO DO MODELO COOPERATIVO EM VIGOR DESDE 1988}

O governo Bolsonaro assumiu em 2019 com muitos bordões prontos. No campo das relações federativas, evocando o modelo tipo-ideal americano, a máxima "Mais Brasil, menos Brasília” resume essa visão influenciada pelo federalismo fiscal (Oates, 1972). Esta concepção argumenta que, em cada nível de governo, os impostos devem estar relacionados com os benefícios que geram para a sociedade. As transferências intergovernamentais seriam suplementares, pois se os governos locais respondem pela maior parte da provisão de políticas públicas, igualmente precisam ser responsabilizados pela geração de receitas próprias.

Para muitos soa como música pensar que o governo central ampliaria a autonomia dos Estados e municípios. Se cada ente federativo recebesse a fatia de recursos que lhe é devida, teria mais liberdade para definir em que aplicar seus recursos e quais as suas prioridades de políticas públicas. No lugar da esfera federal, o protagonismo seria devolvido para os governos subnacionais, o que reduziria ou, no limite, tornaria desnecessária a coordenação federativa. Ao invés do comando centralizado de Brasília, o laissez faire federativo seria o novo desenho da divisão territorial do poder entre as esferas de governo.

Esta concepção é sempre apresentada com o argumento que Estados e municípios vêm sendo penalizados, desde 1988, por um modelo que drena recursos para Brasília e reduz sua capacidade de ação. Por esse raciocínio, coordenação federativa nada mais seria que um eufemismo para a centralização política e financeira da União sobre os demais níveis de governo. Qual seria a saída? Ampliar a autonomia de gastos e de definição de políticas no plano subnacional e reduzir ao máximo o papel do ente federal.

O conceito subjacente a essa proposta ecoa o conhecido debate sobre federalismo dual ou cooperativo, sendo o primeiro visto pelos adeptos de maior liberdade de ação federativa como ideal (Abrucio et al., 2020). Governos podem gastar de forma mais eficiente, tornam-se mais accountable para suas populações, incumbentes ampliam sua responsividade e as políticas públicas respondem melhor às particularidades locais. No entanto, o que importa é o projeto político inserido nessa concepção: compreende-se que vários centros de poder subnacional descentralizados são mais adequados para o funcionamento das instituições federativas. Coordenação federativa seria contingente, circunstancial e, no limite, desnecessária, por gerar mais uma camada governamental que só faz crescer problemas de eficiência decisória e de alocação de recursos.

Em oposição a esse modelo, a CF/88 assentou as bases de um federalismo mais cooperativo, em muito apoiado no artigo 23, que define várias áreas de competência comum entre os três entes. A autonomia subnacional foi fortalecida com mais garantias constitucionais e foram implementadas transferências intergovernamentais visando a mitigar desigualdades regionais (Arretche, 2012). A coordenação intergovernamental cresceu em muitas áreas, sendo o SUS o caso mais avançado (Abrucio, et al., 2021).

Desde então, de forma incremental, o federalismo democrático e descentralizado tornou-se a referência, ao mesmo tempo em que a União, gradualmente, intensificou seu papel de 
coordenação intergovernamental em áreas- chave como saúde e educação (Abrucio, 2005). Nesses mais de 30 anos, ainda que o equilíbrio entre autonomia e coordenação (Arretche, 2004) tenha enfrentado problemas, o acordo básico sobre o desenho político e institucional do federalismo se manteve.

Esse modelo sofreu um forte abalo desde o início do governo Bolsonaro, pois sua visão política do federalismo - "menos Brasília, mais Brasil” -baseia-se na ampliação de autonomia subnacional em desfavor do papel coordenador da União. Trata-se de um federalismo compartimentado mais profundo que a lógica dualista clássica. A COVID-19 escancarou essa concepção do federalismo bolsonarista (Abrucio et al., 2020) em três dimensões. A primeira, a omissão completa para coordenar esforços intergovernamentais baseado em uma dupla compreensão: autocracia federativa - só o governo central tem autoridade para definir regras relativas ao enfrentamento da pandemia - e enfraquecimento das arenas de cooperação federativa.

A segunda, o conflito pautado por uma lógica oportunista que Bednar (2009) chama de burden shifting: o fardo para o combate da pandemia é de governadores e prefeitos, o que intensificou o conflito federativo. Entretanto, sendo a COVID-19 um problema intergovernamental complexo (Paquet \& Schertzer, 2020), sua solução requer coordenação e não conflito federativo.

A terceira, o negacionismo federativo que não reconhece a competência constitucional de Estados e municípios para lidar com a política de saúde e o enfrentamento à pandemia, como definido pelo artigo 23 da CF/88. Conforme Teixeira, Fernandes, Zuccolotto e Nascimento, (2020), um dos mais importantes fatores que marcam a innaction policy do governo federal no combate à COVID-19 é a descoordenação federativa.

Não há mérito algum na ação do governo federal, na arena da cooperação intergovernamental, no combate à pandemia que, de quebra, contribuiu para acelerar a aposta em marcha do federalismo bolsonarista. Parafraseando Melo (1996), e adaptando seu argumento conceitual de 25 anos atrás, o projeto político deste governo é instalar um hobbesianismo federativo no qual cada ente responde pelo seu território, mesmo que isso implique enfrentamentos com outros Estados e/ou municípios. A ausência do governo federal na coordenação intergovernamental para o enfrentamento à pandemia é reveladora de um projeto político centralizador e autoritário. A pandemia desvelou esse modelo em que o governo central aposta no conflito federativo e no enfraquecimento da cooperação intergovernamental.

Nessa linha, três artigos desta edição especial abordam diretamente o conflito federativo associado ao modo bolsonarista de governar.

O texto de Claudio Cesar de Paiva, Raphael Guilherme Araujo Torrezan e Suzana Cristina Fernandes de Paiva, "O federalismo cooperativo em obstrução: fissuras intergovernamentais da pandemia”, analisa fatos e características da resposta brasileira à pandemia que fragilizam e obstruem a descentralização e o federalismo cooperativo. Os autores discutem a possível transição em curso para um federalismo coercitivo (Posner, 2008), que se verifica, por exemplo, pelas tentativas de obstrução dos canais de diálogo entre os representantes de diferentes níveis de governo e o esvaziamento de instituições voltadas às discussões federativas, como fóruns de debates, comitês e conselhos. Os autores concluem que, ao fomentar litigância, incluindo o uso recorrente de ameaças, manobras conflitivas e punições aos governos estaduais e locais que 
apresentavam posicionamentos políticos diferentes do seu no combate da pandemia, o governo federal impede a construção de estratégias institucionais coordenadas e com responsabilidades compartilhadas.

No mesmo sentido, o artigo de Felipe Fróes Couto, Gabriel Farias Alves Correia e Alexandre de Pádua Carrieri, "O antilíder: Da liderança discursiva presidencial à descoordenação federativa para o combate à Covid-19”, analisa criticamente a liderança política do presidente Jair Bolsonaro em relação à coordenação das ações dos demais entes federativos durante a pandemia. Os autores o fazem a partir dos direcionamentos da análise crítica do discurso de Teun A. van Dijk e do método da materialidade audiovisual. Os dados analisados, oriundos de 15 vídeos publicados nos canais oficiais do presidente da República na plataforma YouTube, mostram que a liderança presidencial na coordenação dos entes federativos subnacionais constituiu uma antítese do que é prescrito na literatura sobre liderança pública. Ao se posicionar de maneira agressiva, constituindo um cenário discursivo de guerra contra outras lideranças políticas, o presidente mostra uma postura que pode ser associada à figura de um antilíder. Promove desagregação e descoordenação para buscar favorecer suas próprias concepções.

$\mathrm{O}$ artigo "Federalismo fiscal na pandemia da Covid-19: do federalismo cooperativo ao federalismo bolsonarista”, de Sergio Simoni Junior, Eduardo Lazzari e Heloísa Fimiani analisa a atuação da União no auxílio financeiro aos entes subnacionais. O federalismo fiscal brasileiro durante a pandemia evidencia, segundo os autores, que o governo Bolsonaro empregou uma estratégia de coordenação conflitiva e negativa. A análise mostra que, quando se trata da reposição por meio dos Fundos de Participação de Estados e Municípios, cujos critérios de distribuição são previstos na CF/88, há considerável consenso nas relações ExecutivoLegislativo e entre os partidos. Já na recomposição arrecadatória subnacional, por meio do Programa Federativo de Enfrentamento ao Coronavírus SARS-CoV-2, de iniciativa do Congresso, há clivagens entre o governo e o Legislativo e entre as bancadas estaduais, dividindo os partidos e polarizando Estados ricos e pobres. O vácuo deixado pela tentativa do governo de vetar a proposta foi ocupado por parlamentares de regiões mais pobres, que viram uma oportunidade para aumentar seus ganhos com a ajuda compensatória. A omissão do Executivo fez com que a clivagem regional fosse predominante e levou a resultados subótimos mesmo para atores situados no governo federal.

\section{CONFLITOS JURISDICIONAIS ENTRE UNIÃO, ESTADOS E MUNICÍPIOS DURANTE A PANDEMIA}

A CF/88 definiu o STF como o órgão máximo de defesa das regras constitucionais. Nessa linha, uma competência importante é aquela que o autoriza a processar e julgar as causas e conflitos entre a União, os Estados e o Distrito Federal, ou entre os próprios Estados. O comportamento que tem predominado na arbitragem federativa, orientado pela lógica da simetria federativa, acaba subsumindo o direito federal à defesa das prerrogativas do nível central sobre os governos subnacionais. Esse tipo de decisão pode tomar o julgamento das Ações Diretas de Inconstitucionalidade (ADI) como referência empírica. 
Oliveira (2009) analisa uma série de ADIs e destaca que estas são um instrumento válido para mediar as relações federativas, mas que grande parte das ações não é julgada. Tal comportamento sugere a questão sobre a fragilidade do STF para assumir o papel de salvaguarda federal como tribunal constitucional. O segundo ponto é que, nas ADIs julgadas, o governo federal tem sido o grande vencedor desde a entrada em vigor da CF/88. Canello (2017) baseia-se em um banco de dados de ações do STF e mostra que este se comporta como um ator majoritariamente próUnião, com poucos casos de decisões favoráveis aos Estados. São analisadas 145 ações movidas pelos Estados contra a esfera federal, das quais apenas 11 foram consideradas procedentes, 3 parcialmente procedentes, 54 tiveram decisões em favor da União, 7 foram encerradas e as demais 70 (aproximadamente metade) aguardam julgamento. A União, por sua vez, requer muito menos o apoio do STF: no total, foram nove ações contra governadores, Estados, prefeitos e municípios, com apenas uma prejudicada e o restante aguardando julgamento.

Na mesma linha, Barbosa (2014) argumenta que o STF protege o poder central em processo de que a União é parte, o que se reflete em elevado percentual de ações a serem julgadas. Portanto:

O Supremo Tribunal Federal não atua como árbitro do federalismo brasileiro, nem para equilibrar o jogo federativo. Na verdade, a omissão do Supremo, ou o seu ativismo judicial negativo mantém o status quo no plano regional, cujos custos políticos e econômicos de se anular políticas fiscais e tributárias já sedimentadas pelo tempo são demasiadamente elevados, e protege a União Federal no plano nacional As políticas fiscais e tributárias já arraigadas pelo tempo são muito elevadas e protegem a União Federal para nível nacional” (p. 63).

Essa afirmação fica evidenciada empiricamente: no conflito horizontal (entre entes subnacionais), os processos levam em média 2,5 anos para serem julgados, enquanto no conflito vertical (que envolvem a União) a média é de 3,1 anos.

Por outro lado, Abrucio et al. (2020) mostram uma mudança nesse comportamento do STF. O estudo analisa os impactos da pandemia COVID-19sobre o federalismo bolsonarista e suas ações visando a desequilibrar os pilares estabelecidos na CF/88 quanto à distribuição de competências entre os três entes da federação. O pano de fundo para a decisão do STF, no auge da pandemia, foi um conflito criado pelo presidente contra governadores e prefeitos sobre medidas de fechamento de estabelecimentos e outras de enfrentamento à COVID-19. O $\mathrm{STF}$, com base no artigo 23 da CF/88, validou as ações dos Estados e municípios e rejeitou a Medida Provisória $n^{\circ}$ 926/2020, que buscava centralizar todo o combate à pandemia nas mãos do governo federal como inconstitucional. O ponto central da decisão foi o argumento de que, sendo a saúde pública competência comum dos três níveis federativos, na ausência do nível superior, os entes subnacionais não estavam impedidos de estabelecer medidas sanitárias de combate à pandemia. O STF atuou confirmando a autonomia de Estados e municípios para a adoção de medidas restritivas de prevenção à disseminação do vírus.

Embora seja cedo para dizer que uma mudança de rumo está em andamento, foi uma decisão importante, considerando o longo histórico de medidas em favor do governo federal. Pode ser que, em situações em que o interesse da maioria da sociedade é confrontado pelo nível federal, talvez o STF venha a adotar decisões a favor dos governos subnacionais se estes 
são os que defendem o interesse coletivo. O fato é que a pandemia mostrou ao menos uma decisão relevante do STF que contrariou sua postura dominante de decidir em favor da União nos conflitos federativos.

Nessa linha, segue o artigo de Fernanda Leoni, "O papel do Supremo Tribunal Federal na intermediação dos conflitos federativos no contexto da Covid-19”, que analisa uma amostra de 22 decisões do STF - 18 ADIs e quatro Ação de Descumprimento de Preceito Fundamental (ADPF), no período de março de 2020 a março de 2021. O estudo demonstra que, mesmo durante a pandemia, a posição da Corte manteve a tendência centralista favorecendo as competências da União em face de outros entes federados na solução dos conflitos federativos. Ainda que, em alguns casos, o STF tenha pontuado a relevância da harmonia no exercício de competências comuns pelos entes federativos.

No texto "Agendas e conflitos no contexto da pandemia da Covid-19: Um olhar a partir da realidade do Rio Grande do Norte”, Raquel Silveira, Anderson Cristopher dos Santos, Lindijane de Souza Bento Almeida, Ana Mônica Medeiros Ferreira, Edson Lucas Pereira dos Santos e Raquel de Carvalho Cardoso analisam a influência do Poder Judiciário na agenda pública e na solução de conflitos, no contexto da pandemia da Covid-19, relativos às políticas econômica, de saúde, de educação e de assistência social. Considerando dados sobre processos e sentenças judiciais da Justiça estadual e federal, no Rio Grande do Norte (RN), entre março de 2020 e abril de 2021, os autores discutem a multiplicidade de conflitos levados à apreciação pelo Judiciário como reflexo de conflitos sociais, políticos e interfederativos. Dada a inexistência de coordenação nacional por parte do governo federal, coube aos Estados e municípios uma resposta governamental a partir do contexto e da correlação de forças locais, acirradas pelos conflitos nacionais. O cenário de disputas de cunho federativo e político no RN trouxe à tona a competição e a fragilidade refletidas na judicialização de demandas na saúde e, sobretudo, em relação a medidas econômicas adotadas pelos entes federados.

\section{O PAPEL E A ATUAÇÃo do SUS NO COMBATE À PANDEMIA}

O SUS desempenhou um papel central no enfrentamento à COVID-19. A inexistência desse arranjo tripartite de política pública teria cobrado um preço ainda maior de mortos e pessoas com sequelas decorrentes da infecção pelo vírus. Sobretudo, considerando que o aumento da pobreza e extrema pobreza só fez crescer a demanda pelos serviços públicos de saúde.

Contudo, considerando o desenho institucional e federativo do SUS, qual foi o seu papel no âmbito das relações intergovernamentais? Foi o SUS capaz de manter o modelo de cooperação federativa que foi definido na Lei Orgânica da Saúde em 1990? Conforme Massuda, Malik, Vecina Neto, Tasca, e Ferreira Junior (2021), o SUS possui como fortalezas a coordenação unificada e descentralização de serviços organizada por complexidade em redes regionais hierarquizadas que permitem cobrir todo o território nacional. Instrumentos de cooperação e planejamento intergovernamental em nível regional aproximam as esferas de governo, sobretudo Estados e municípios. O modelo de governança federativa pautado pela descentralização de serviços para os entes subnacionais busca compensar a descoordenação por meio de arranjos 
verticais de cooperação, como são a Comissão Intergestoras Tripartite (CIT) e as Comissões Intergestoras Bipartite (CIBs)

Essa arquitetura organizativa do SUS - descentralização com coordenação federativa que envolve União, Estados e municípios - enfrentou seu maior teste de resiliência institucional (Keenan, 2020) no combate à pandemia. Não bastasse a crise sanitária, o enfrentamento à pandemia colocou o SUS em rota de colisão com o governo Bolsonaro. Some-se a este problema conjuntural o crescente subfinanciamento ao longo dos anos, que foi acentuado pelo teto de gastos em vigor desde 2016. Na saúde, as despesas federais caíram em relação à receita corrente líquida: de 16,1\% em 2017 para 13,9\% em 2019 (Cavalcante \& Nogueira, 2020). Foi nesse contexto de colisão política e perda de recursos que o SUS teve que atuar no combate à pandemia.

De um lado, apesar dos problemas de subfinanciamento e das dificuldades de gestão, a atuação do SUS é muito valorizada, principalmente por proporcionar um sistema público universal para um país que é muito desigual em população e em termos territoriais (Massuda et al., 2018). No que diz respeito ao federalismo, um estilo híbrido de políticas públicas de saúde foi estabelecido, fundindo aspectos majoritários (alto poder regulatório e de indução financeira nas mãos do governo federal) e características consociativas (implementação descentralizada e fóruns de deliberação federativa) (Grin \& Abrucio, 2019). Vale frisar que as normas do SUS definem que o governo federal também deve tratar de questões de âmbito nacional, como situações de pandemia. No entanto, no início da crise sanitária, o governo federal procurou centralizar as decisões no Ministério da Saúde.

Considerando esse desenho de política intergovernamental, com seus avanços e limites, a influência do desenho institucional do SUS foi vital para fortalecer a cooperação intergovernamental tripartite no enfrentamento à pandemia. A CIT e as CIBs foram fundamentais para atuar como salvaguardas institucionais e intergovernamentais contra decisões federais mais unilaterais. Se esses órgãos de coordenação não existissem, a cooperação federativa seria ainda mais debilitada para lidar com a pandemia e decidir sobre temas operacionais, financeiros e administrativos que afetam a atuação de Estados e municípios (Segatto \& Béland, 2019). Não fosse a existência de um modelo institucionalizado de cooperação federativa e gestão compartilhada (Franzese, 2010) que funciona há quase três décadas, a descoordenação intergovernamental seria ainda mais pronunciada.

Mesmo que a governança federativa do SUS apresente fragilidades, e haja redução dos repasses federais para Estados e municípios, a resiliência de seu desenho institucional mostrou-se capaz de resistir aos ataques promovidos pelo governo federal. Por outro lado, Massuda et al. (2021) destacam fragilidades do SUS que foram exacerbadas pela pandemia. O modelo municipalista autárquico de provisão de serviços, que permitiu a capilaridade territorial de uma rede básica de saúde, também criou obstáculos para fortalecer os instrumentos de cooperação federativa, como as comissões intergestoras e os consórcios intermunicipais, que foram insuficientes para integrar redes assistenciais municipais e estaduais em regiões de saúde. Ainda assim, cidades consorciadas lograram melhores resultados na redução do número de mortos pela COVID19(Grin et al., 2021b). 


\section{OS ESTADOS E AS FORMAS DE COOPERAÇÃO E COORDENAÇÃO NO NÍVEL SUBNACIONAL PARA O ENFRENTAMENTO DA PANDEMIA}

A partir da Lei Federal n ${ }^{\circ}$ 13.979/2020, que dispõe sobre medidas a serem adotadas para o enfrentamento da emergência, os Estados e municípios passaram a elaborar decretos que regulamentassem medidas visando a enfrentar o estado de emergência de saúde pública decorrente do novo Coronavirus (SARS-CoV-2). Muitas foram as dificuldades de Estados e municípios no relacionamento e busca de apoio do governo federal, seja na liberação de recursos para enfrentamento da pandemia, seja na habilitação e no custeio de leitos de terapia intensiva para o enfrentamento da doença.

Ademais, as mensagens do governo federal eram contra as medidas de isolamento, já provadas necessárias e instituídas em países que lograram êxito na diminuição do contágio do vírus SARS-COV-2. A adoção de medidas através da cooperação federativa subnacional impôs-se aos prefeitos e governadores, sobretudo, para suprir lacunas deixadas intencionalmente pelo governo federal. A presidência, em direção oposta aos prefeitos e governadores, optou por contrariar as evidências científicas e as recomendações internacionais exitosas na mitigação da COVID-19. Os governadores dos 26 Estados brasileiros e do Distrito Federal, no início da pandemia, criaram o Fórum Nacional dos Governadores para discutir a crise e, em diversos momentos, colocar-se contra a posição do presidente com relação à COVID-19.

Quanto às vacinas, a postura de descaso demonstrada pelo governo federal fez com que governadores e prefeitos saíssem em busca da vacina de forma independente da União. Foi o caso do governo do Estado de São Paulo, por meio do Instituto Butantan, da Universidade de São Paulo (USP), em parceria com a farmacêutica Sinovac, da China, que produziu e distribuiu no país a Coronavac. Nessa linha, também a formação do "Conectar", consórcio nacional liderado pela Frente Nacional de Prefeitos para a aquisição de vacinas contra a COVID-19e que, recentemente, discutiu formas de comprar vacinas para crianças de 5 a 11 anos.

A atitude de governadores e prefeitos em busca da vacina gerou pressão política para que o governo federal passasse a se mobilizar para a sua compra e distribuição. Com efeito, a atuação e articulação dos governadores foi fundamental na reação do país à posição negacionista $\mathrm{e}$ inepta do presidente Bolsonaro.

Por outro lado, também houve competição entre os Estados para a compra de respiradores e equipamentos de segurança para os profissionais de saúde. Houve também discordâncias no âmbito do Fórum de Governadores, ainda que tenha prevalecido a atuação coordenada como contraponto ao governo federal.

Outro aspecto da atuação de Estados e municípios foi a divulgação de informações sobre a pandemia para atualizar bases de dados nacionais, que subsidiam o trabalho de cientistas e jornalistas, e para esclarecer a população sobre cuidados com a doença, medidas de prevenção, tratamento e vacinação. O Conselho Nacional de Secretários de Saúde (CONASS) funcionou como instância de articulação e divulgou informações e orientações ao longo da pandemia. Estados e capitais que se destacaram em rankings de transparência da pandemia contribuíram para que outros governos também avançassem. Colaboraram para isso, por 
exemplo, pesquisadores de universidades e organizações que estimularam a abertura de dados (OKBR, 2021). A imprensa, diante de da falta de segurança nas informações disponibilizadas pelo Ministério da Saúde, recorreu às secretarias estaduais para obter dados sobre a pandemia. Além disso, vários governadores e prefeitos adotaram postura protagonista na comunicação com o público, por diversas mídias, em contraponto ao negacionismo do presidente. E fizeram-no de maneira personalista, institucional, ou coordenada, como em manifestações e decisões conjuntas.

A cooperação intergovernamental horizontal para o processamento de informações é um dos destaques do artigo de Joel Mendoza Ruiz, nesta edição especial, "Dos experiencias mexicanas de Relaciones Intergubernamentales: Influenza A/H1Nl en la competición y COVID-19 en la contracción". A análise busca identificar em que aspectos a experiência do México na resposta à Influenza A/H1N1, em 2009, contribuiu para melhorias na sua resposta à atual pandemia de COVID-19, e quais deles estão relacionados à cooperação intergovernamental. Dos seis tipos de ações analisadas, o único que mostra avanço associado à cooperação entre governos subnacionais foi verificado no processamento de informações, que tende a ser institucionalizado na organização horizontal de governadores, inclusive tendo resultado em uma proposta de reforma no texto constitucional. Duas outras linhas ou tipos de ação analisadas mostraram avanços na atual pandemia, em relação a 2009, ainda que estes não possam ser imputados à cooperação intergovernamental. Verificaram-se retrocessos em três dos seis tipos de ação analisadas, porém sem relação evidente com aspectos de coordenação federativa.

\section{POLÍTICAS ADOTADAS POR GOVERNOS SUBNACIONAIS, VISANDO AO BEM-ESTAR SOCIAL E À MITIGAÇÃO DE DESIGUALDADES SOCIOECONÔMICAS DURANTE A PANDEMIA}

O fortalecimento da coordenação federativa, sobretudo por meio de sistemas nacionais de políticas, qualificou a implementação de políticas nacionais por Estados e municípios brasileiros. Da mesma forma, geraram-se efeitos positivos na construção de capacidades estatais subnacionais e na redução de desigualdades regionais (Arretche, 2012; Bichir et al., 2020; Grin \& Abrucio, 2019). O que foi verificado no Brasil reforça os argumentos da literatura internacional de que mecanismos de coordenação são centrais para a expansão das políticas de welfare e a garantia de direitos sociais universais em Federações (Obinger,Leibfried, \& Castles 2005).

No entanto, ainda que a coordenação nacional tenha sido central induzindo a adoção de determinadas políticas por governos subnacionais, há variações nas políticas subnacionais (Bichir, Brettas, \& Canato 2017; Gomes, 2009; Segatto, 2018). Compreender que fatores no nível subnacional influenciam essas variações é fundamental para avançar na discussão sobre federalismo e políticas públicas.

Essa questão é ainda mais relevante no contexto da pandemia em que prevaleceu a ausência de coordenação nacional, o que motivou os governos subnacionais a adaptarem e criarem políticas próprias. No que se refere às desigualdades socioeconômicas, os distribuíram cestas básicas, criaram programas de transferência de renda, distribuíram equipamentos e aumentaram o 
acesso à Internet para os alunos das escolas estaduais e municipais. No entanto, sem coordenação nacional, e com uma trajetória de frágil coordenação estadual que marca a maioria das políticas e dos Estados, prevaleceram respostas fragmentadas e descoordenadas no nível subnacional.

De um lado, emergiram lógicas competitivas e de credit claiming e blame avoidance, como foram os casos no nível nacional do Auxílio Emergencial e do Programa Nacional de Apoio às Microempresas e Empresas de Pequeno Porte (PRONAMPE) (BRASIL, 202la). O programa foi retomado em 2021 pelo Ministério da Economia e convertido em permanente pelo Senado. Foi também retomado o Programa Emergencial de Manutenção do Emprego e Renda (BEM), por meio da Medida Provisória n ${ }^{\circ}$ 1.045/2021 (BRASIL, 2021b). Entretanto, esses programas foram insuficientes em termos nacionais para conter os efeitos que a pandemia trouxe à crise econômica. Estados e muitas prefeituras de capitais implementaram programas de renda mínima com auxílios mensais para trabalhadores informais, programas de microcrédito para comerciantes formais e informais, assim como parcelamento de ICMS pelos governos estaduais, entre outras medidas complementares e de compartilhamento de competências entre os entes.

De outro lado, essas respostas dos entes subnacionais foram heterogêneas e de caráter emergencial. Em muitos casos, os programas foram modestos em termos monetários e nos prazos de concessão de benefícios. Porém, deve-se considerar que a Federação brasileira é bastante desigual, especialmente em capacidades fiscais e administrativas dos governos subnacionais, ainda mais desafiadas e limitadas com a pandemia. Mesmo assim, cabe reter que, em geral, os entes subnacionais não fugiram de sua responsabilidade e muitos seguem implementando seus programas de auxílios e, em alguns casos, planejando torná-los permanentes. Porém, essa heterogeneidade interfederativa pode também reforçar as desigualdades que a pandemia exacerbou.

\section{INOVAÇÃO SUBNACIONAL, INSTRUMENTOS E MECANISMOS DE COORDENAÇÃO DESENVOLVIDOS NA PANDEMIA}

A descoordenação federativa durante a pandemia foi a regra. Mesmo assim, dado que o federalismo brasileiro pressupõe esferas de poder e competências entre os três níveis de governo, algumas iniciativas importantes e inovadoras de Estados e municípios visando a ajudar a combater a pandemia foram desenvolvidas.

Em 2020, quando ainda não existiam vacinas, e durante o primeiro semestre de 2021, quando a vacinação estava muito lenta no Brasil, vis-a-vis o aumento da velocidade da proliferação do vírus, gerou-se um grande estresse para o SUS, mobilizando equipes, serviços e leitos de UTI por longos períodos para tratamento das pessoas afetadas pela doença. Algumas medidas, tanto políticas, quanto no front de atendimento das unidades intensivas, ajudaram a diminuir as curvas de contágio e o número de casos e óbitos e a melhorar as estruturas de atendimento médico-hospitalar para o cuidado dos doentes.

Uma dessas medidas inovadoras resultou da cooperação interfederativa por meio do Consórcio Nordeste - formado pelos nove Estados da região, orientado pela atuação conjunta em muitas áreas e focado no desenvolvimento sustentável . O Consórcio Nordeste instituiu um comitê científico de apoio ao combate à pandemia da COVID-19para assessorar os Estados na 
adoção de medidas para a prevenção e o controle de riscos da disseminação do vírus, bem como auxiliar na estruturação do SUS para o atendimento da população. O comitê, sob a coordenação do cientista Miguel Nicolelis, foi composto por especialistas em áreas como saúde coletiva, clínica médica, direito sanitário, gestão pública, ciência da computação, engenharia clínica, e epidemiologia. Buscou-se assim dar suporte aos governadores na tomada de decisões com base em evidências científicas e boas práticas internacionais. Foram implementadas medidas como compras conjuntas de insumos e equipamentos, implantação de sistema eletrônico de monitoramento da COVID-19, coleta de informações sobre o estado clínico dos cidadãos e capacitação de recursos humanos.

No âmbito da complexidade das relações intergovernamentais e da divisão entre competências comuns no federalismo brasileiro, Estados e municípios estão aptos a desenvolver inovações locais e costumam partilhar estas experiências. Algumas delas são guindadas ao nível nacional, se validadas pelas instâncias federais competentes. Este foi o caso, no âmbito do SUS, da criação do capacete respirador Elmo. Desenvolvido por pesquisadores do Estado do Ceará e aprovado pela ANVISA (Unifor, 2020), o Elmo foi importante no atendimento de pacientes com COVID-19 que necessitavam de ar, pela insuficiência respiratória aguda causada pela doença.

\section{O PANORAMA DO COMBATE À PANDEMIA NOS PAÍSES FEDERAIS: EXPERIÊNCIAS E APRENDIZAGENS}

A pandemia de COVID-19vem gerando aprendizagens sobre e para o federalismo, em vários países. O artigo convidado para esta edição especial, "Impact of COVID-19 on the comparative practice of federalism: Some preliminary observations”, de autoria de Rupak Chattopadhyay, Felix Knüpling e Diana Chebenova, do Fórum das Federações, apresenta um panorama do combate à pandemia em 24 países federais ou com arranjos similares de organização territorial do Estado. Os dados resultaram de uma survey aplicada em cada país. A comparação das respostas à pandemia nesses países, de uma perspectiva de governança, permitiu identificar três categorias: i) respostas dominadas pelo governo nacional; ii) colaboração e coordenação intensa entre diferentes níveis de governo e; iii) colaboração frágil entre as esferas de governo.

Os autores analisam características dessas três categorias, destacando achados. Entre eles, a contribuição do federalismo para a aprendizagem intergovernamental e a inovação; o crescimento da digitalização na administração, na oferta de serviços públicos e na comunicação interna e entre governos e cidadãos; a erosão da capacidade fiscal subnacional; e o fato de governos locais emergirem como atores relevantes na resposta à pandemia.

\section{CONSIDERAÇÕES FINAIS}

O federalismo tem sido um dos temas centrais no processo de enfrentamento à pandemia no Brasil. Moderando um pouco a afirmação, no mínimo, uma questão contextual relevante. De todo modo, o "teste de estresse" do arranjo federativo gerado pelo pacto constitucional de 1988 ao longo do ano de 2020 só fez aprofundar e deixar transparente a visão do atual governo. 
Se vale a referência ao debate clássico, o federalismo bolsonarista atua para desconstruir as bases da cooperação intergovernamental e encontra-se mais próximo do modelo dualista. $\mathrm{O}$ enfrentamento à pandemia acelerou esse projeto político, pois a inação do governo central ficou evidenciada de várias formas, em especial na política de saúde.

Por outro lado, a resiliência política e institucional do federalismo brasileiro mostrou-se capaz de enfrentar a lógica centralizadora e conflitiva posta em marcha pelo governo central no âmbito das relações intergovernamentais. Considerando a literatura sobre salvaguardas federativas (Bednar, 2009), as conhecidas como estruturais, relativas às prerrogativas constitucionais de Estados e municípios ("poderes enumerados"), não foram afetadas. O redesenho do federalismo fiscal não avançou (por exemplo, o debate sobre as emendas constitucionais com os temas da desindexação e desvinculação dos valores dos fundos nacionais transferidos para áreas como saúde e educação). Quanto à salvaguarda judicial, mesmo sendo exagerado afirmar que houve um turning point com a decisão do STF, a decisão em favor de Estados e municípios foi um exemplo de afirmação do princípio federativo. A partir de abril de 2020, o governo federal ficou impedido, com base na CF/88, de implementar o que Bednar (2009) e Posner (2008) chamam de um federalismo oportunista que se expressa, dentre outras formas, por processos de encroachment da esfera central na autonomia subnacional.

$\mathrm{Na}$ esfera intergovernamental, o SUS e seu arranjo de cooperação intergovernamental desempenhou um papel importante de reação (contenção da usurpação de prerrogativas de Estados e municípios, afirmando sua vocação de um sistema único, o que é diferente de ser nacional) dos arroubos autoritários da esfera central. Se trajetórias e desenho institucional das políticas públicas contam (Pierson, 2000), a política de saúde foi capaz, no mínimo, de evitar a centralização da condução do enfrentamento à pandemia no Ministério da Saúde. Por outro lado, a ausência de coordenação federal também teve efeitos negativos, dada a importância de organizar as ações com os três níveis de governo para o enfrentamento da pandemia, como ocorreu em outras federações (Segatto, Béland, \& Dinan, 2021). Por exemplo, a competição entre os Estados para a compra de equipamentos de proteção e respiradores ou a desastrosa condução do governo federal na aquisição de vacinas.

A pandemia também gerou consequências não previstas para o federalismo brasileiro, sendo duas de destacada importância. A primeira foi incentivar e reforçar a cooperação interestadual, fortalecida por meio de arranjos consorciados (e.g. Consórcio Interestadual de Desenvolvimento do Brasil Central, Consórcio Interestadual de Desenvolvimento Sustentável da Amazônia Legal, Consórcio de Integração Sul e Sudeste, Consórcio Interestadual de Desenvolvimento Sustentável do Nordeste). A crise desencadeada pela COVID-19intensificou a cooperação e a coordenação entre os governadores que já vinha ocorrendo pelo vazio de autoridade política e o conflito federativo iniciado pelo presidente Bolsonaro desde 2019.

Ainda será preciso verificar se os Estados seguirão avançando na sua agenda de atuação coletiva. Porém, não se pode descartar que a conjuntura crítica desencadeada pela pandemia venha a ser o estímulo para fortalecer o Fórum de Governadores e a cooperação horizontal entre os Estados. A experiência internacional mostra que a barganha e a negociação federativa tendem a ser mais equilibradas quando se fortalece com a organização coletiva dos governadores. 
Outro efeito relevante foi na linha do "laboratório do federalismo", com as inovações subnacionais tendo adquirido vitalidade como forma de enfrentar a pandemia em um contexto de isolamento social, necessidade de incentivar alternativas de emprego e renda e de mitigar a crise social e do desemprego (De la Cruz, Grin, Sanabria-Pulido, Cravacuore, \& Orellana, 2020). Também no âmbito municipal, cabe destaque para os consórcios intermunicipais que assumiram um papel fundamental para a definição de medidas comuns de combate à COVID19(e.g. decretos comuns de lockdown), possibilitando a aquisição mais barata de medicamentos e equipamentos de proteção para profissionais de saúde, como máscaras e luvas, bem como para a provisão de serviços especializados que as cidades sozinhas não conseguiriam obter (Grin et al. 2021b).

O balanço da COVID-19 no Brasil está longe de positivo, mas as instituições políticas e regras do federalismo brasileiro mostraram que, por diferentes ângulos, foram capazes de exercer um papel relevante para lidar com um problema intergovernamental complexo (Paquet \& Schertzer, 2020). Espera-se que esta Edição Especial contribua para o debate do federalismo brasileiro que resultou do pacto constitucional de 1988, passando pelo choque da pandemia e indicando perspectivas para as relações intergovernamentais e o federalismo pós-COVID-19.

\section{REFERÊNCIAS}

Abrucio, F. L. (2005). A coordenação federativa no Brasil: A experiência do período FHC e os desafios do Governo Lula. Revista de Sociologia e Política, 24, 41-67. doi:10.1590/s010444782005000100005

Abrucio, F. L., Sano, H., \& Sydow, C. T. (2010). Radiografia do associativismo territorial brasileiro: Tendências, desafios e impactos sobre as regiões metropolitanas. In J. Klink (org.). Governança das metrópoles: conceitos, experiências e perspectivas (pp. 21-48). Annablume.

Abrucio, F.L., Grin, E.J., Franzese, C., Segatto, C.I., \& Couto, C.G.. (2020). Combating COVID-19 under Bolsonaro's federalism: A case of intergovernmental incoordination. Revista de Administração Pública, 54(4), 663-677. doi: 10.1590/0034-761220200354x

Abrucio, F.L., Grin, E. J., \& Segatto, C. I. (2021). Brazilian federalism in the pandemic. In: B. G. Peters, E. J. Grin e F. L. Abrucio. American federal systems and covid-19. Responses to a Complex Intergovernmental Problem (pp. 63-88). Emerald Publishing.

Arretche, M. (1996). Mitos da Descentralização: Maior Democracia e Eficiência nas Políticas Públicas? Revista Brasileira de Ciências Sociais, 11(31), 44-66.

Arretche, M. T. S. (2004). Federalismo e políticas sociais no Brasil: Problemas de coordenação e autonomia. São Paulo em Perspectiva, 18(2) 17-26. doi: 10.1590/S0102-88392004000200003

Arretche, M. T. S. (2012). Democracia, Federalismo e Centralização. Rio de Janeiro: Editora FGV; Editora Fiocruz.

Arretche, M. T. S., Marques, E., \& Faria, C. A. P. de (orgs.). (2019). As políticas da política: Desigualdades e inclusão nos governos do PSDB e do PT. Editora Unesp. 
Barbosa, L. V. (2014). Guerra fiscal e o ativismo judicial negativo: Mapeando o conflito federativo no Supremo Tribunal Federal. Revista Política Hoje. 23(2), 43-66. Retrieved from https://periodicos.ufpe.br/revistas/politicahoje/article/view/3741

Bednar, J. (2009). The robust federation. Principles of design. Cambridge University Press.

Béland, D., Rocco, P., Segatto, C. I., \& Waddan, A. (2021). Trump, Bolsonaro, and the Framing of the COVID-19 Crisis: How Political Institutions Shaped Presidential Strategies. World Affairs, 184(4), 413-440. doi: 10.1177/00438200211053314

Bichir, R.; Brettas, G. H.; Canato, P. (2017). Multi-level governance in federal contexts: The Social Assistance Policy in the City of São Paulo. Brazilian Political Science Review, 11(2), 1-28. doi: 10.1590/1981-3821201700020003

Bichir, R. M., Simoni Júnior, S., \& Pereira, G. (2020). Sistemas nacionais de políticas públicas e seus efeitos na implementação. O caso do Sistema Único de Assistência Social (Suas). Revista Brasileira de Ciências Sociais, 35(102), 1-23. doi: 10.1590/3510207/2020

BRASIL. Garantindo emprego e renda. Gov.br, Brasília, DF, Jun. 19, 202 la. Retrieved from https://bit.ly/321LrWl.

BRASIL. Receita Federal define regras sobre Pronampe 2021b. Gov.br, Brasília, DF, Jul 2. 2021. Recuperado de https://bit.ly/3kH9q3H

Canello, J. (2016). Judicializando a Federação? O Supremo Tribunal Federal e os atos normativos estaduais (Doctoral Thesis). Universidade do Rio de Janeiro, Rio de Janeiro.

Cavalcante, P. L. \& Nogueira, R. A. (2020). Crise fiscal e reforma do Estado: Uma análise longitudinal das contas públicas federais. In: P. L. Cavalcante \& M. S. Silva (Eds.). Reformas do estado no Brasil: Trajetórias, inovações e desafios. (p. 83-110). IPEA.

CEAPG. Centro de Estudos em Administração Pública e Governo (2021). Programa Gestão Pública e Cidadania. FGV EAESP. Recuperado de https:/eaesp.fgv.br/centros/centroestudos-administracao-publica-e-governo/projetos/programa-gestao-publica-e-cidadania.

De la Cruz, E.E.R, Grin, E.J., Sanabria-Pulido, P., Cravacuore, D., \& Orellana, A. (2020). The Transaction Costs of Government Responses to the COVID-19 Emergency in Latin America. Public Administration Review, 80(4), 683-695. doi: 10.1111/puar.13259

Fernandes, A.S.A., \& Wilson, R.H. (2013). Mudança institucional e gestão metropolitana no Brasil: O municipalismo autárquico e as finanças municipais metropolitanas. Revista de Administração Pública 47(3), 1-24. doi: 10.1590/S0034-76122013000300011

Franzese, C. (2010). Federalismo Cooperativo no Brasil: Da Constituição de 1988 aos Sistemas de Políticas Públicas. (Doctoral Thesis). Escola de Administração de Empresas de São Paulo, São Paulo.

Gil, A.G. (2021). Princípio federativo e conflitos de competências constitucionais: Uma análise sob o enfoque da gestão de crise da saúde pública na Pandemia de Covid-19. Revista de Ciências do Estado. 6(1), 1-19. doi: 10.35699/2525-8036.2021.25986

Gomes, S. (2009). Políticas nacionais e implementação subnacional: Uma revisão da descentralização pós-Fundef. Dados, 52(3), 659-690. doi: 10.1590/S001 1-52582009000300004 
Grin, E. J. (202 la). Capacidades políticas locais e a realidade dos consórcios intermunicipais na federação brasileira. In: E. J. Grin, D. J. Demarco e F. L. Abrucio (Eds.). Capacidades estatais municipais: O universo desconhecido no federalismo brasileiro (pp. 317-365). Editora UFRGS.

Grin, E. J. et al. (2021b). Together it is possible to go further: Brazilian health inter-municipal consortium as a collaborative and innovative governance to fight COVID-19. Paper presented at International Research Society for Public Management. Anais.

Grin, E. J. \& Abrucio, F. L. (2018). Quando nem todas as rotas de cooperação intergovernamental levam ao mesmo caminho: Arranjos federativos no Brasil para promover capacidades estatais municipais. Revista do Serviço Público, 69(Edição especial), 85-122. doi: 10.21874/ rsp.v69i0.3584

Grin E. J. \& Abrucio, F. L. (2019). The co-evolutionary policy style of Brazil: Structure and functioning. In: M. Howlett \& J. Tosun (Eds.). Policy styles and policy-making: exploring linkages. (pp. 115-1360). Routledge.

Julião, K. S. \& Olivieri, C. (2020). Cooperação intergovernamental na política de saúde: A experiência dos consórcios públicos verticais no Ceará, Brasil. Cadernos de Saúde Pública, 6(3), 1-12. doi: 10.1590/0102-311X00037519

Keenan, J. M. (May, 2020). COVID, resilience, and the built environment. Environment systems Æ decisions, 40, 216-221 doi: 10.1007/s10669-020-09773-0

Licio, E. C., Palotti, P., Meneses, A. D. F. P., \& Pontes, P. A. D. M. M. (2021). Governos estaduais na execução das políticas sociais: Saindo de cena? Boletim de Análise PolíticoInstitucional. Recuperado de http://repositorio.ipea.gov.br/handle/1 1058/10933? mode=full

Lui, L., Schabbach, L. M., \& Nora, C. R. D. (2020). Regionalização da saúde e cooperação federativa no Brasil: O papel dos consórcios intermunicipais. Ciência \& Saúde Coletiva, 25(12), 5065-5074. doi: 10.1590/1413-812320202512.03752019

Massuda, A.; Hote, T.; Leles, F. A. G.; \& Castro, M. C. (2018). The Brazilian health system at crossroads: progress, crisis and resilience. BMJ Glob Health, 3(4), e000829. Recuperado de https://pubmed.ncbi.nlm.nih.gov/29997906/

Massuda, A. Malik, A. M., Vecina Neto, G., Tasca, R., \& Ferreira Junior (2021). A resiliência do Sistema Único de Saúde frente à COVID-19. Cadernos Ebape, 19, Edição especial, 73574. doi:10.1590/1679-395120200185

Melo, M.A. Crise Federativa, Guerra-Fiscal e Hobbesianismo Municipal: As Vicissitudes da Descentralização. São Paulo em Perspectiva, 10(3), 11-20. Recuperado de https://pesquisa. bvsalud.org/portal/resource/pt/lil-413092

Oates, W. (1972). Fiscal federalism. Instituto de Estudios de Administración Local.

Obinger, H., Leibfried, S., \& Castles, F. G. (Orgs) (2005). Federalism and the welfare state: New World and European experiences. Cambridge University.

OKBR, Open Knowledge Brasil (2021). Emergência dos dados. Como o Índice de Transparência da Covid-19 impulsionou a abertura de dados da pandemia no Brasil. Recuperado de https:// ok.org.br/wp-content/uploads/2021/11/Ebook_EmergenciaDados_OKBR.pdf 
Oliveira, V. E. (2009). Poder Judiciário: Árbitro dos conflitos constitucionais entre Estados e União. Lua Nova, 78, 223-250. doi: 10.1590/S0102-64452009000300011

Paquet, M., \& Schertzer, R. (2020). COVID-19 as a Complex Intergovernmental Problem. Canadian Journal of Political Science, 53(2), 1-5. doi: 10.1017/S0008423920000281

Pierson, P. (2000). Increasing Returns, Path Dependence, and the Study of Politics. The American Political Science Review, 94(2), 251-267. Recuperado de https://www.tandfonline. com/doi/full/10.1080/13597566.2017.1409732

Posner, P. (2008). Mandates: The politics of coercive federalism. In: T. J. Conlan, \& P. L. Posner, (Eds.). Intergovermental Management for the 21st century (pp.286-309). The Brookings Institute.

Segatto, C. I. (2018). Policy diffusion in subnational governments: State-local relationships in the Brazilian education policy. Regional \& Federal Studies, 28(1), 79-100. doi: $10.1080 / 13597566.2017 .1409732$

Segatto, C. I., \& Abrucio, F. L. (2018). Os múltiplos papéis dos governos estaduais na política educacional brasileira: Os casos do Ceará, Mato Grosso do Sul, São Paulo e Pará. Revista de Administração Pública, 52(6), 1179-1193. doi: 10.1590/0034-761220170047

Segatto, C. I., Béland, D., \& Dinan, S. (2021). Canadian Federalism in the Pandemic. In: B. G. Peters, E. J. Grin \& F .L. Abrucio (Eds.). American federal systems and COVID-19. Responses to a Complex Intergovernmental Problem (pp. 89-106). Emerald Publishing.

Segatto, C. I. \& Béland, D. (2019). Federalism and decision making in health care: The influence of subnational governments in Brazil. Policy Studies, 42(3), 308-326 doi:10.1080 /01442872.2019.1634187

Silva, A. L. N. da. (2020). Os Estados Importam! Determinantes da cooperação subnacional nas políticas de educação e saúde do Brasil. (Doctoral Thesis). Fundação Getúlio Vargas, São Paulo, São Paulo.

Teixeira, M. A. C., Fernandes, A. S. A., Zuccolotto, R., \& Nascimento, A. B. (2020). The Brazilian Government's Inaction Policy in the face of the COVID-19 pandemic: Federative uncoordination, insufficient financial resources and political crisis. GIGAPP ESTUDIOS WORKING PAPERS, 7, pp. 533-554, Recuperado de http://www.gigapp.org/ewp/index. php/GIGAPP-EWP/article/view/227/233

Unifor (November, 2020). Anvisa autoriza produção do capacete Elmo em escala industrial. Recuperado de https://www.unifor.br/-/anvisa-autoriza-producao-em-escala-industrial-docapacete-elmo

Viana, A. L. D’á., Ibanez, N., Elias, P. E. M., Lima, L. D., Albuquerque, M. V., \& Iozzi, F. L. (2008). Novas Perspectiva da Regionalização da Saúde. São Paulo em Perspectiva, 22(1), 92106. Recuperado de https://pesquisa.bvsalud.org/portal/resource/pt/lil-527705 